\title{
Experiências com etnomatemática na escola carlos Marighella: narrativas de um professor
}

\section{Experiences with ethnomathematics at the carlos school Marighella: narratives of a teacher}

DOI: 10.54018/sssrv2n3-005

Recebimento dos originais: 05/07/2021

Aceitação para publicação: 20/08/2021

\section{Ujeffesson Marques Silva}

Licenciado em Educação do Campo com habilitação em Matemática pela Universidade Federal do Sul e Sudeste do Pará (UNIFESSPA), Especialista em Educação do Campo Agricultura Familiar e Currículo pelo Instituto Federal do Pará - Campus Rural Marabá. Mestrando pelo Programa de Pós-Graduação em Ciências e Matemática. (PPGECM - UNIFESSPA)

E-mail: ujeffesson@gmail.com

\section{Rosemeri Scalabrin}

Doutora em Educação, professora EBPT - IFPA. Possui pós doutorado em Ciências da Educação na especialidade Desenvolvimento Curricular

\section{Deise Aparecida Peralta}

Doutora em Educação para Ciências. Docente na UNESP. Possui pós doutorado em Ciências da Educação, na especialidade Desenvolvimento Curricular

\section{RESUMO}

O presente trabalho é fruto de minha pesquisa desenvolvida ao longo do curso de Especialização em Educação do Campo Agricultura Familiar e Currículo, Instituto Federal do Pará (IFPA), Campus Rural Marabá. A pesquisa teve como objetivo discutir minha experiência como professor de matemática na escola Carlos Marighella, a partir de narrativas constituídas por memórias evocadas, considerando a perspectiva da Etnomatemática. A mesmas foi realizada na Escola M.E.F. Carlos Marighella, localizada no assentamento 26 de março no município de Marabá - Pará. A pesquisa foi desenvolvida a partir de uma experiência desenvolvida com a turma de $4^{\circ}$ ano do ensino fundamental, tendo como base o ano letivo de 2019. Esta pesquisa caracteriza-se como autobiográfica, tendo as minhas narrativas como professor de matemática. Como constituição de dados, assim como a memória de experiências pessoais e profissionais como elemento basilar de investigação. Como pressuposto, este estudo estabelece o ideário que memória do narrador (reconstrutiva da significação de suas vivências) e os instrumentos de análise e interpretação do pesquisador são elementos que se imbricam e complementam para melhor compreensão de dimensões da realidade autobiográfica pesquisada, tanto na perspectiva pessoal/social do narrador, como na perspectiva contextual da atuação do professor como produto/produtor de conhecimento sobre ensino de matemática na perspectiva da Etnomatemática. Para tanto tomo como base 
teórica D’Ambrósio que me ajuda a compreender a Etnomatemática; Knijink que me ajuda a articular educação popular e a Etnomatemática, e Bosi (1979) e Grazzition (2016) que me fundamentam sobre discutir minhas memórias como produção de conhecimentos. Como resultados mostro como fotografias são evocadores de minhas memórias e têm o potencial de me subsidiar na interpretação de minha experiência como professor de matemática.

Palavras-chave: Etnomatemática. Memórias. Fotografia. Narrativas. Práticas Pedagógicas.

\section{ABSTRACT}

The present work is the result of my research developed during the course of Specialization in Education of the Field, Family Farming and Curriculum, Instituto Federal do Pará (IFPA), Campus Rural Marabá. The research aimed at discussing my experience as a mathematics teacher at Carlos Marighella school, from narratives constituted by evoked memories, considering the Ethnomathematics perspective. It was carried out at Escola M.E.F. Carlos Marighella, located in the 26 de Março settlement in the municipality of Marabá - Pará. The research was developed from an experience developed with the 4th grade class of elementary school, based on the 2019 school year. This research is characterized as autobiographical, having my narratives as a mathematics teacher. As data constitution, as well as the memory of personal and professional experiences as the basic element of investigation. As an assumption, this study establishes the idea that the narrator's memory (reconstructive of the meaning of his experiences) and the researcher's instruments of analysis and interpretation are elements that intertwine and complement each other for a better understanding of the dimensions of the autobiographical reality researched, both from the narrator's personal/social perspective and from the contextual perspective of the teacher's performance as a product/producer of knowledge about mathematics teaching from the perspective of Ethnomathematics. To this end, I take as my theoretical basis D'Ambrósio, who helps me to understand Ethnomathematics; Knijink, who helps me to articulate popular education and Ethnomathematics, and Bosi (1979) and Grazzition (2016), who support me in discussing my memories as a production of knowledge. As results I show how photographs are evocative of my memories and have the potential to subsidize me in interpreting my experience as a mathematics teacher.

Keywords: Ethnomathematics. Memories. Photography. Narratives. Pedagogical Practices.

\section{INTRODUÇÃO}

A pesquisa que resultou na produção desse artigo pode ser caracterizada dentro do amplo espectro de pesquisas autobiográficas que, ao mesmo tempo que utiliza de diversas fontes (tais como narrativas, história oral, fotos, vídeos, filmes, diários, documentos em geral), reconhece-se determinada pelas 
memórias ${ }^{1}$. Nesse sentido, o professor pesquisador se assume como narrador de suas memórias. Toma-se a ação do narrador como (re)construção de elementos de análise que possam auxiliá-lo na compreensão da sua experiência como professor de matemática. A pesquisa autobiográfica estabelece diálogo entre o individual e o sociocultural, pois "põe em evidência o modo como cada pessoa mobiliza seus conhecimentos, os seus valores, as suas energias, para ir dando forma à sua identidade, num diálogo com os seus contextos". (MOITA, 1995, p. 113).

Os estudos autobiográficos referem-se as vidas em meio a pluralidade de tempos sociais e cronológicos e as memórias são as evidências, passíveis de acesso, a possibilidades de encadeamento entre esses tempos (BOURDIEU, 1987). Consonante à perspectiva de ter, no próprio pesquisador, o narrador que recupera memórias, narra as vivências e analisa as próprias experiências como autor no mundo social.

\section{REVISÃO DE LITERATURA}

\subsection{MATEMÁtICA, CURRÍCULO, EDUCAÇÃO DO CAMPO E} ETNOMATEMÁTICA UMA ARTICULAÇÃO POSSÍVEL

O ensino de matemática vem ganhando novas dimensões a partir de estudos e realização de pesquisas, com destaque para área da Educação Matemática com ênfase na Etnomatemática, levando para sala de aula os conhecimentos construídos por grupos sociais e culturais ao longo tempo, porém ainda há escolas que têm ensino de matemática baseado somente na matemática escolar formal, desconsiderando os saberes construídos pelos sujeitos ao longo do seu processo formativo.

Entendemos aqui por matemática escolar aquela presente, tradicionalmente, nos livros e manuais didáticos amparados em currículos que privilegiam os conhecimentos de origem e desenvolvimento eurocêntricos. Nesse sentido, o que se tem enraizado nos currículos escolares é uma concepção de ensino que privilegia ideais e modelos europeus, notadamente, com ênfase no

\footnotetext{
${ }^{1}$ Memória nesta pesquisa trata-se de memória individual do pesquisador que também se assume narrador na perspectiva de Walter Benjamin, em relação imbricada às vivências vivenciais - sociais e culturais - e por elas informada/significada/ressignificadas como experiências pessoais e profissionais.
} 
masculino e nas culturas colonizadoras.

Em relação à manutenção de supremacias, Ubiratan D'Ambrósio, explica que ao "longo da história, o currículo é organizado como reflexo das prioridades nacionais e do interesse dos grupos que estão no poder" (D'AMBRÓSIO, 2017, p.63). O que nos permite inferir que a educação praticada se volta a suprir as necessidades dos poderosos, desconsiderando o conhecimento dos sujeitos que são social e culturalmente constituídos. A concepção explicitada pelo Prof Ubiratan se mantém atual e se mostra muito presente no cotidiano escolar. É inegável a forte tendência de ensino voltado para suprir os interesses da elite.

Apesar dos movimentos que discutem educação articulada às demandas dos povos do campo, colocando em pauta a luta por escolas e currículos estruturados a partir da vivência, da cultura, das experiências e saberes dos grupos sociais; o imperativo sistêmico próprio da relação de dominação coloniza as escolas com práticas de ensino que desconsideram os sujeitos e suas as realidades. Quando se fala em educação dos povos do campo, algo alarmante sempre soa, pois, além do difícil acesso dessas pessoas à educação formal, temos a não contextualização do ensino que, ainda baseado apenas nos livros didáticos, não legitima a experiência dos cotidianos vivenciados.

Os Parâmetros Curriculares Nacionais (PCN) já alertava sobre a necessidade de abordagens para o ensino de matemática a partir das vivências dos sujeitos, articulando com o contexto social, defendendo "que a aprendizagem da Matemática esteja ancorada em contextos sociais que mostrem claramente as relações existentes entre o conhecimento matemático[...]" (BRASIL, 1998, p.79). Assim, podemos perceber que ensinar matemática, a partir de elementos presentes na vida dos sujeitos, cumpre um papel fundamental para a vida dos mesmos, possibilitando uma visão mais crítica perante a sociedade.

Segundo Tomaz e David (2008)

A matemática escolar passa a ser vista como um meio de levar o aluno à participação mais crítica na sociedade, pois a escola começa a ser encarada como um dos ambientes em que as relações sociais são fortemente estabelecidas." (TOMAZ; DAVID, 2008, p.15).

O ensino, não só da matemática, mas de todos os demais componentes disciplinares, está sujeito à dinamicidade do desenvolvimento curricular que, por sua vez, não escapa ao dinamismo social e cultural dos diferentes lugares e 
espaços de interação dos sujeitos, e aqueles que deveriam ser considerados por esses sujeitos como elementos de reflexão sobre as questões da sociedade em que vivem.

Ao aceitar que a escola tem um papel fundamental na constituição identitária dos sujeitos, ela "[...]pensada como parte de um projeto maior de educação[...] se propõe a construir uma prática educativa que efetivamente fortaleça[...]para as lutas principais" (MOLINA; SÁ, 2012, p. 326) e que, em decorrência, a matemática com sentido não só no ambiente escolar, mas também na vida social do estudante, dependendo da forma como é apresentada impacta de diferentes maneiras nas identidades a serem construídas.

Ela pode (re) afirmar existências e resistências se for elemento de discussão, partindo de cenários conhecidos e vivenciados pelos estudantes. Por isso, a contextualização nos currículos escolares tem sido apontada como princípio para pensar a Educação do Campo que, articulada à interdisciplinaridade, orienta os processos para além de uma racionalidade técnica na formação.

De acordo com Tomaz e David (2008)

[...] a interdisciplinaridade, pode ser esboçado por meio de diferentes propostas, com diferentes concepções, entre elas, aquelas que defendem um ensino aberto para a inter-relações entre a Matemática e outras áreas do saber cientifico ou tecnológico, bem como com as outras disciplinas escolares. (DAVID; TOMAZ, 2008, p. 14)

Porém, para que a contextualização e a interdisciplinaridade caminhem em conjunto é necessário que os professores conheçam a realidade dos estudantes para que possam buscar conteúdos consonantes às realidades vivenciadas pelos mesmos, fazendo com que eles se tornem sujeitos capazes de questionar e interferir nas questões e decisões da sociedade e de sua vida cotidiana.

Um dos problemas enfrentados por esses sujeitos, é o distanciamento dos conteúdos ensinados com os saberes e as práticas desenvolvidas pelos povos do campo. Nesse sentido, D’Ambrósio afirma que

Uma grande dificuldade do processo educacional é que o professor não conhece o ambiente cultural dos estudantes e, portanto, fica difícil reconhecer o que o estudante já sabe e o que é capaz de fazer. (D'AMBRÓSIO, 2008, p.10). 
Esse não (re)conhecimento contribui para esse distanciamento entre os conteúdos escolares e as práticas vivenciadas pelos sujeitos, provocando, muitas vezes, desinteresse nos estudantes em aprender a matemática ao não perceberem a utilidade da matemática escolar para sua prática diária.

É preciso que a educação matemática reconheça [...] que nossos alunos estão vivendo em dois mundos distintos [...] mesmo quando estão na matemática escolar, a maioria das pessoas não pratica essa matemática na rua[...]. (LINS; GIMENEZ, 2006, p. 17-18).

O diálogo entre a matemática escolar e a matemática praticada pelos sujeitos em suas vidas é importante, pois torna possível uma forma de matematizar pertencente a cada família/grupo social, garantindo à matemática escolar um novo significado para os sujeitos. Esse diálogo se tornou pauta de reivindicações por uma educação que se contraponha aos interesses de um currículo hegemônico.

Hoje, após luta de movimentos sociais, a Educação do Campo tem se orientado pela interlocução com a cultura, as práticas, os saberes construídos e vivenciados pelos diferentes povos/grupos sociais, defendendo que o ensino ofertado para os povos do campo e da cidade pode ser contextualizado a partir da realidade local. Apesar das discussões, tanto dos movimentos sociais como da academia a partir dos cursos de Educação do Campo, ainda há trabalho pedagógico organizado de forma descontextualizada e desconectada das práticas desenvolvidas pelos povos da localidade em que trabalha. Isto posto, talvez em decorrência do não conhecimento ou não adesão ao paradigma de uma educação própria do campo e do povo do campo (Educação do Campo) em alternativa ao que, historicamente, vinha sendo praticada como uma educação ditada para o povo do campo (Educação para o Campo), podendo essa última ser ilustrada no imaginário educacional pela escola rural que adaptava conteúdos pensados para a escola urbana.

Apesar da compreensão de educação contida nas práticas e na elaboração teórica que tem estruturado o conceito de Educação do Campo estender-se para além da dimensão escolar, reconhecendo e valorizando as diferentes dimensões formativas presentes nos processos de reprodução social nos quais estão envolvidos os sujeitos do campo, parte relevante deste movimento tem se dado em torno da luta pela redução das desigualdades no direito à educação escolar no território rural. (MOLINA; SÁ, 2012, p.466) 
Desta forma, é possível perceber que a Educação do Campo reconhece os saberes produzidos pelos sujeitos nos mais diversos espaços de vivências, ou ainda para além do ambiente escolar. No entanto, ainda há escassez de políticas públicas de formação de professores, para atuarem nas escolas do campo, fundamentadas em epistemologias próprias da dinâmica da vida e do povo do campo, e assim, há professores que trabalham no campo, mas que não levam em consideração a realidade vivenciada por seus estudantes.

\begin{abstract}
A escola tem praticado usualmente a política do conhecimento dominante, uma política que compartimentaliza, engaveta em gavetas incomunicáveis o conhecimento do mundo, nos fazendo pensar ser "natural" que a escola esteja organizada por disciplinas, que o tempo e o espaço escolar sejam distribuídos entre as aulas de Matemática, as aulas de História, as aulas de Português, de Ciências e as horas de recreio (segundo os estudantes, os melhores momentos de sua vida estudantil). (KNIJNIK, 2004, p.3)
\end{abstract}

A partir dessa afirmação, a autora vem reforçar aquilo que as escolas historicamente vêm praticando, um currículo que não valoriza os saberes.

Uma das possiblidades de buscarmos trabalhar os conteúdos a partir de uma outra perspectiva, é produzir livros didáticos que podem abordar diferentes realidades, tanto da cidade como do campo e, que os professores precisam de uma formação que os direcionem a trabalhar partindo dessa realidade. Nesse sentido, a Educação do Campo vem contrapor o formato de ensino tradicional, ou seja, trabalhar os conteúdos de forma segmentada, encerrado na disciplina, surgindo com o princípio de trabalhar os conteúdos de forma interdisciplinar e contextualizada, considerando o meio social e cultural em que se encontram os sujeitos.

Para mais, "o trabalho interdisciplinar implica em atividades de aprendizagem que favoreçam a vivência de situações reais ou simulem problemas e contextos da vida real que, para serem enfrentados, necessitarão de determinados conhecimentos e competências" (MELO, s.d., p.8), ou seja, o ensino a partir da vivencia dos sujeitos implica uma maior inserção dentro de nossa sociedade e uma melhor compreensão dos fenômenos a partir do olhar integrado de várias disciplinas. 


\section{PROCEDIMENTOS METODOLÓGICOS}

Para realização da pesquisa, o percurso metodológico adotado ocorreu em duas etapas, sendo:

i) O evocar das memórias por meio da fotografia

Segundo Bosi (2009), a interação do pesquisador (narrador) com materiais auxiliares à rememoração é um instrumento potente de pesquisa autobiográfica. A fotografia nesta pesquisa é utilizada como um desses materiais, auxiliando no trabalho de rememorar, de (re)construir e evocar memórias. As fotografias usadas neste processo evocador de memórias, não tomam sentidos de produção de verdade sobre as experiências de ensino de matemática, mas de buscar ver além da imagem, adentrando nos caminhos história que cada fotografia carrega e que são rememoradas ao serem vistas.

Esta etapa envolveu reunir fotografias que retratassem momentos de minhas experiências como professor na escola em que também vivenciei tempos como estudante.

As fotografias selecionadas foram tiradas por mim, enquanto professor, pois desde que iniciei minha docência sempre busquei registrar momentos que julgo importante, para quando eu quiser rememorar alguns desses momentos, poder recorrer as fotografias que me ajudam nesse processo. As vezes essas fotos eram tiradas pelos educandos, utilizando meu celular e pelos meus colegas de trabalho, também com meu dispositivo telefônico, fotos essas tiradas ao longo do ano letivo de 2019, dentro das mais diversas atividades trabalhadas, na qual eram registrados momentos ímpares dentro de minha prática docente com a referida turma.

Ao longo de minha graduação, principalmente em pesquisa de campo, que ocorriam tanto no desenvolvimento de algumas disciplinas durante o período presencial, quanto no tempo comunidade, eram registradas por fotografias as atividades realizadas. Isso foi tornando-se uma prática que tomei para mim, tanto na vida pessoal, quanto profissional, pois esses registros me ajudam a voltar ao passado e aguçar a minha memória, no sentido de relembrar fatos que marcaram minha história.

A história dessas fotos está intrinsicamente ligada com minha atuação profissional, pois elas demonstram momentos educacionais em que foi abordado 
com metodologias inovadoras, além de servir como um instrumento para que eu repense e avalie essas metodologias. Quando revisito esses registros, trago em minhas memórias lembranças de sujeitos, espaços, conhecimentos construídos, momentos únicos que me fazem seguir e continuar nessa luta, na defesa de uma educação de qualidade, educação essa que tenha sentido na vida dos educandos, que cumpra um papel social, políticos e cultural.

A escola Carlos Marighella, dentro do município de Marabá-Pará, possui um diferencial entre as escolas do campo, por ser a única escola dentro do município que trabalha em tempo integral, na qual passamos uma maior quantidade de tempo com os educandos na escola, em que possibilita desenvolver outras atividades tendo em vista esse tempo. Além disso, o currículo da escola trabalha com vários momentos, a saber: tempo aula, tempo oficina, tempo horta, sala de leitura, sala de informática, e foram nesses momentos que busquei trabalhar de forma integrada.

Desta forma, essas fotografias selecionadas foram tiradas principalmente em atividades de campo, em que os educandos iam à campo para realizar atividades integradas com aquelas desenvolvidas em sala de aula, fazendo um diálogo e explorando o meio em que estão inseridos.

Em um primeiro momento, foram selecionadas 04 fotografias que de início julgava ser suficiente para a discussão no presente trabalho, mas, ao longo da escrita fui percebendo algumas lacunas, que a partir de então busquei outras fotografias que me ajudou nesse processo de rememoração, na qual trouxe mais 06 fotografias. É importante aqui esclarecer, que as fotografias selecionadas não eram somente as que eu tinha armazenadas, existem outras fotografias que não foram abordadas no trabalho.

Algumas dessas fotos estão armazenadas na memória do meu dispositivo telefônico, tanto na memória interna, quando na externa (cartão SD). Além da memória do meu dispositivo, essas fotos estão armazenadas no meu Google fotos na internet (Plataformas Google), como um meio de maior segurança para que eu não perca essas imagens e acabar caindo no esquecimento momentos marcantes na minha história de vida.

Destaco aqui, que essas fotos são todas minhas, não tive que pedir a outras pessoas, apesar de ter realizado várias atividades em conjunto com outros 
professores e outras turmas, eu era quem fazia os registros fotográficos.

ii) Narrativas sobre experiencia: Organização das memórias

Esta etapa se desenvolve a partir da organização das memórias que, evocadas pelas fotografias, foram reunidas e tecidas em narrativas, dando origem a um texto que registra e analisa as minhas experiências como professor de matemática. De acordo com GRAZZIOTIN (2016):

\begin{abstract}
A memória é movediça e subjetiva; não se encontra previamente organizada; seu arquivo não está em ordem alfabética nem cronológica. Não se encontra em uma gaveta ou em um armário e, embora tenha grande potencial como fonte histórica, precisa ser produzida e organizada pelo pesquisador. (GRAZZIOTIN, 2016, p. 166).
\end{abstract}

Nesta perspectiva Este trabalho de investigação que tem fontes em narrativas relacionadas às minhas memórias, ultrapassa as barreiras de "dar voz" às minhas vivências e põe-se a discutir as minhas experiências que se estabelecem entre o vivido e o por mim concebido. Neste processo, sob a perspectiva ao referencial teórico, minhas narrativas são fontes problematizadas e analisadas a partir do que sou hoje. E nesse sentido, as memórias evocadas se ressignificam a partir do que penso hoje na perspectiva da Etnomatemática no ensino de matemática. Portanto, nesta etapa, as memórias tornam-se narrativas no presente a partir dos fragmentos de experiências do passado.

\title{
4 RESULTADOS
}

\subsection{A ETNOMATEMÁTICA COMO VIA ALTERNATIVA PARA O ENSINO DE} MATEMÁTICA: UM ESTUDO A PARTIR DA HORTA ESCOLAR

$\mathrm{Na}$ sociedade em que vivemos, encontramos muitas barreiras quando propomos um ensino diferenciado, um ensino que leve em consideração os aspectos social, político e cultural em que nossos estudantes estão inseridos. Nessa perspectiva, a implementação de uma proposta curricular que atenda esses anseios é vista com más olhares pela sociedade, principalmente quando envolve a questão do trabalho como metodologia de ensino para ensinar conteúdo do saber/saber escolar.

Nesse sentido, ao longo de minha atuação como docente, busquei desenvolver um ensino que levasse meus estudantes a desenvolver um pensamento crítico, formando-os sujeitos capazes de interferir nas decisões pertinente à sociedade em que vive. Quebrar essas barreiras não foram fáceis e, 
ainda não são. Desta forma, destacarei aqui uma das minhas experiências desenvolvidas com estudantes do $4^{\circ}$ ano do Ensino Fundamental na Escola M. E.F. Carlos Marighella, uma escola que busca desenvolver um ensino voltado a realidade dos estudantes.

Uma das atividades desenvolvidas ao longo do ano letivo de 2019 foi trabalhada a partir da horta escolar, na qual era realizado um diálogo entre os conteúdos desenvolvido em sala de aula, com os elementos presentes na horta escolar, reconhecendo "[...]que esses estudantes não chegam à escola com "a cabeça vazia", ou, como dizem alguns filósofos da educação, a mente humana não é uma tabula rasa" (D’AMBRÓSIO, 2008, p. 10).

Freire (2003), que se contrapõe ao modelo de educação que vinha permeando ao longo do desenvolvimento e constituição da sociedade brasileira, educação essa que tinha como princípio a valorização da cultura europeia, transformando o sujeito submisso às exigências das classes dominantes e formar sujeito para que tenham mão de obras para servir a essa classe. Portanto a formação do povo brasileiro não se dá a partir de uma cultura própria, de uma mentalidade permeável, flexível e democrático do homem brasileiro, mas sim de uma educação que rompe com os aprendizados desses sujeitos. Nesse mesmo sentido Romaneli (2001) concorda com Freire (2003), e consonante a esses autores temos também o filme Desmundo (2003), ao retratarem a realidade da formação da cultura do povo brasileiro, onde eram submetidos a uma cultura de origem europeia, não tendo vez e nem voz e, com isso cria-se essa submissão a classe dominante, "Assim vivemos todo nosso período de vida colonial. Pressionados sempre. Quase sempre proibidos de crescer. Proibidos de falar. A única voz, no silêncio a que éramos submetidos, que se podia ouvir, era a do púlpito" (FREIRE, 1967, p 75), em contrapartida, a essa visão de educação, eu busco desenvolver minhas metodologias, levando em consideração o meio cultural em que esses sujeitos estão inseridos.

O primeiro momento dessa atividade consistiu em buscar adubos para colocar na horta, na qual os estudantes tem participação ativa, deste a construção até o consumo das hortaliças plantadas pelos mesmos, ressaltando que essas atividades estão diretamente ligadas aos conteúdos ensinados em sala de aula, ou seja, reconhecendo "[...] que todo estudante, na verdade todo indivíduo, conhece 
muito, possui explicações e modos de fazer, os quais vêm de seu ambiente cultural, de sua cultura, de suas experiências prévias" (D’AMBRÓSIO, 2008, p.10).

$\mathrm{Na}$ imagem abaixo podemos observar o momento em que os estudantes fazem o recolhimento do adubo a ser colocado nos canteiros.

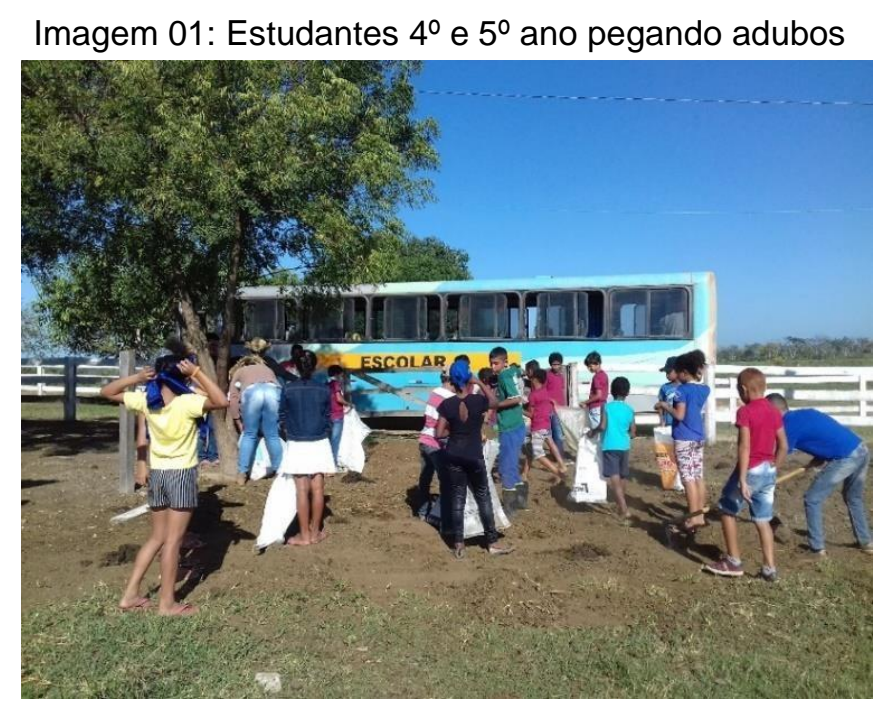

Fonte: silva, 2019

A imagem 01 representa o momento em que os educandos vão para campo nos lotes dos camponeses, fazendo o recolhimento de adubo para poder preparar o solo em que será feito a plantação das hortaliças. Destaco que essas atividades antes de serem desenvolvidas, passam por um momento de reflexão em sala de aula, fazendo um estudo e análise, trazendo relatos dos estudantes, bem como de camponeses integrante da comunidade, e trabalhando os conteúdos do saber escolar, fazendo uma relação com suas práticas diárias como nos fala D’Ambrósio, (2008, p. 11), “É importante levar práticas à escola.

Após o recolhimento do adubo, ele é levado até o ao espaço escolar. Os estudantes em outro momento partem para o processo de adubação dos canteiros, para posteriormente fazerem os plantios e os cuidados necessário para manutenção dos mesmos, como podemos observar na imagem 02. 
Imagem 02: Momento de preparação e adubação dos canteiros

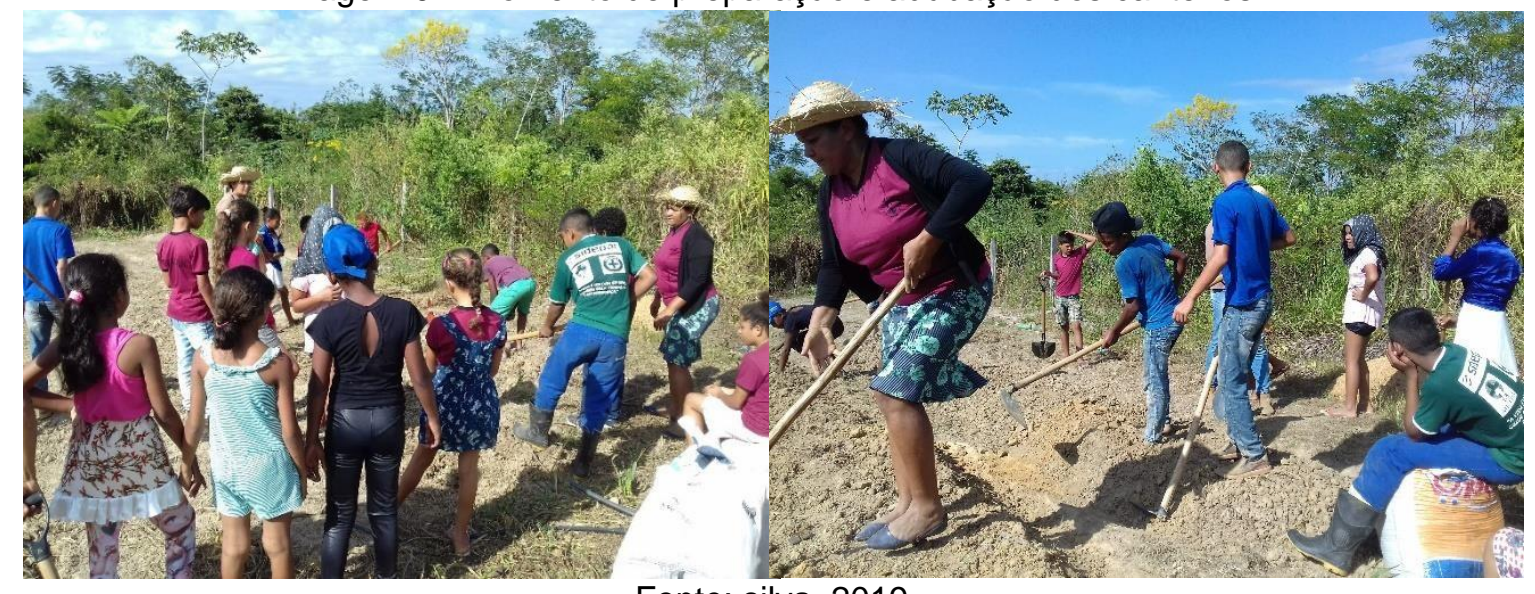

Fonte: silva, 2019

Nas imagens acima, os educandos estão fazendo o preparo, correção e adubação do solo para o plantio das mudas, um momento em que se percebe um maior envolvimento e engajamento da turma, além de ser um momento que propicia para desenvolver a aprendizagem. Diante disso, e na perspectiva de fortalecer o meio em que o educando está vivenciando, busco em meio as minhas práticas educativas, levar dentro de minhas metodologias, um ensino que fortaleça suas culturas, raízes, crenças, dentre outros, pois, somos sujeitos dotados de conhecimentos que se constrói ao longo do processo de formação. Assim, creio que para se construir uma educação de qualidade e que venha contribuir para o desenvolvimento do educando, se faz necessário e urgente, que ousemos em nossas praticas docentes.

Durante esses momentos, os estudantes são levados a refletir acerca dos conteúdos abordados em sala de aula e relacionar com as atividades que a maioria dos estudantes desenvolvem com a família e, dentro do ambiente escolar seus saberes empíricos são utilizados como contribuição na prática pedagógica. Destacando os princípios da Etnomatemática defendido por D’Ambrósio, na qual ele nos diz que "A Etnomatemática propõe uma pedagogia viva, dinâmica, de fazer o novo em resposta a necessidades ambientais, sociais, culturais, dando espaço para a imaginação e para a criatividade" (D’AMBRÓSIO, 2008, p.10). Dentro dessas atividades, percebe-se que os estudantes conseguem assimilar de forma significativa os conteúdos, facilitando o processo de ensino e aprendizagem, na qual podem ver na prática aquilo que está sendo estudado, assim, o estudante passa a perceber de que forma os conteúdos trabalhados em sala de aula está 
presente em suas práticas diárias.

Essas metodologias adotadas vem em contramão aos programas educacionais que vem constituindo a educação brasileira, na qual a nossa formação vem sendo submetida a uma formação alheia a cultura brasileira, em que as escolas desconsideram os saberes em que desenvolvemos ao longo do nosso processo de formação, as culturas, as crenças, os saberes adquiridos de geração para geração, apagando assim toda uma memória de formação do sujeito, impregnando uma nova cultura, um novo conceito, desconstruindo todos os seus saberes.

Para facilitar melhor nosso entendimento e compreendermos de que forma podemos explorar as atividades desenvolvidas em sala de aula com essas atividades práticas, trago um exemplo. $\mathrm{Na}$ imagem 02 , em que os estudantes estão construindo os canteiros no formato retangular, foram explorados os seguintes assuntos: figuras geométricas planas, perímetro, espaçamento, medidas, tipos solos, adubação de solo, misturas, relato de experiência, produções textuais de diferentes gêneros, entre outros. Desta forma, as atividades tiveram uma outra dinâmica e um outro significado no processo de ensino e aprendizagem, como aquelas destaca D’Ambrósio (2017) dentro do programa Etnomatemática.

Ao reconhecer que o momento social está na origem do conhecimento, o programa, que é de natureza holística, procura compatibilizar cognição, história e sociologia do conhecimento e epistemologia social, num enfoque multicultural" (D’AMBRÓSIO, 2005, p.103).

Percebam que, dentro de um único espaço, podemos explorar um leque de conhecimento/aprendizagem, além de tornar uma aula agradável, abordando as práticas vivenciadas por esses sujeitos e, acordo com Freire (1987) tornando-os protagonistas e construtor de seus próprios conhecimentos.

Outro momento que se destaca dentro desse processo, cito o momento da plantação das sementes e das mudas, há uma participação ativa dos estudantes, principalmente por se verem parte integrante do processo. A imagem 03 representa um desses momentos. 
Imagem 03: Estudantes do $4^{\circ}$ ano plantando sementes

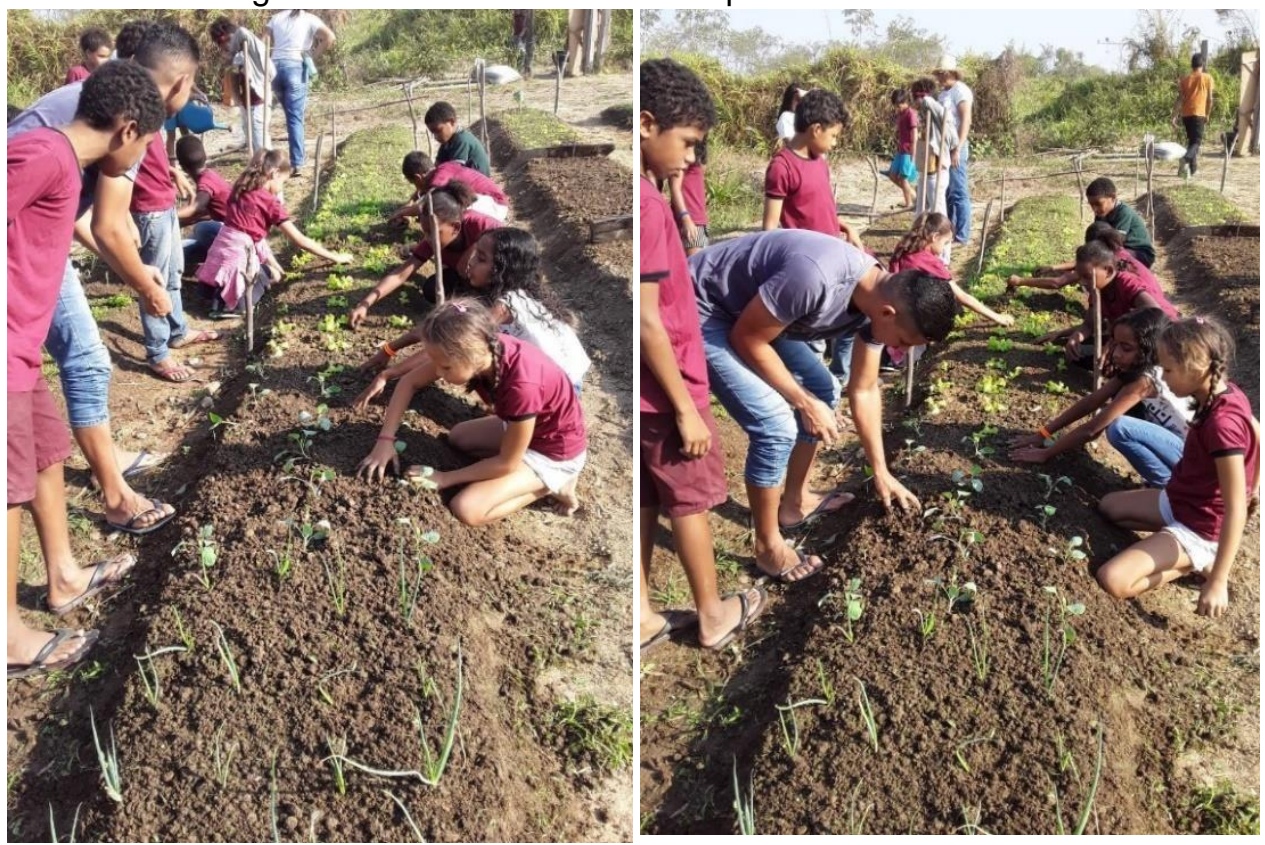

Fonte: silva, 2019

Ao olhar para essas imagens, vejo avanços, possibilidades, transformação, dentre outros aspectos. Além disso, essas imagens me fazem refletir, que ao me ver fazendo parte desse processo, e olhando a época em que fui estudante da referida escola, percebo o quanto consegui avançar enquanto pessoa, estudante, professor, integrante da comunidade, e que todo esse processo teve e tem grandes contribuições dentro de minhas práticas.

Suleiman (2013), nos diz que se faz necessário que as escolas juntamente com os professores desenvolvam práticas de ensino que levem em consideração os diversos fatores existentes na vida dos estudantes e em nossa sociedade de forma geral. Outro fator interessante, trago pela autora, cabe a nós professores inserir dentro das nossas salas de aula um fator indispensável dentro de um processo educativo, a pesquisa, que irá despertar nos estudantes a curiosidade e a necessidade de estar em constante busca pelo conhecimento, como destaca a autora, "[...] a sala de aula pode proporcionar um ambiente em que o conhecimento passa a ser construído por meio da pesquisa que revela e amplia algo que já existia, enriquece e favorece a aprendizagem elaborada pelos próprios estudantes" (SULEIMAN, 2013. p.241).

$\mathrm{Na}$ imagem 04, que veremos a seguir, mostra o momento pós construção das leiras e plantação das mudas e sementes, em que esses estudantes fazem a manutenção e limpeza da mesma e, que não está dissociado com o que está 
sendo explorado em sala.

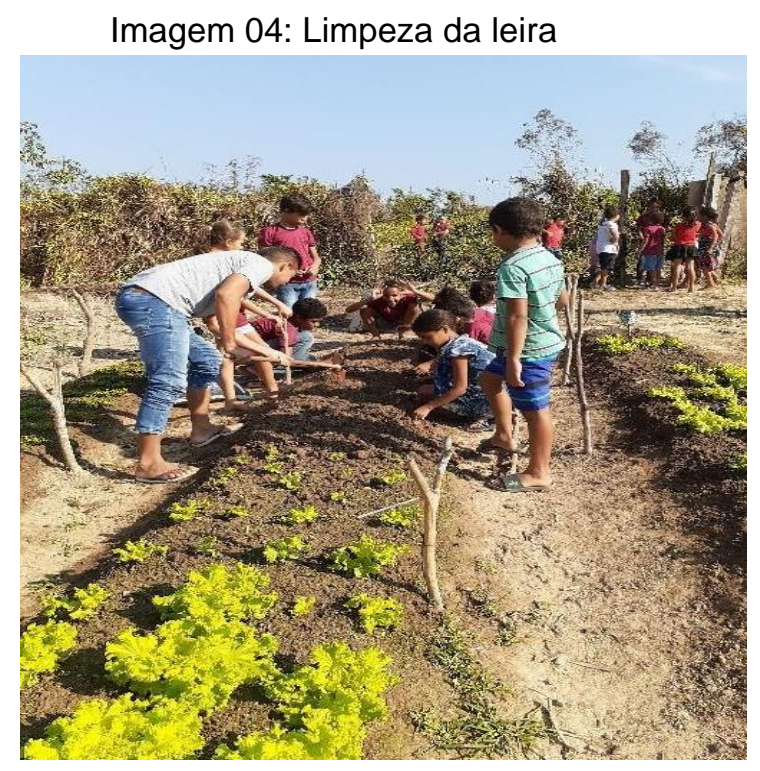

Fonte: Silva, 2019

Propiciar momentos como esse, no processo de formação é fazer com que esses sujeitos se tornem cidadãos atuantes em nossa sociedade, desenvolvendo pensamento crítico, fortalecendo suas culturas e raízes. Nesse processo, é importante enfatizar que os estudantes tiveram a oportunidade de fazer a relação entre teoria e prática e, assim os conteúdos passaram a se relacionar entre os saberes escolares, cientifico com os saberes cotidianos, desta forma, contribuindo para valorização da cultura desses sujeitos. Devemos ressaltar, que as práticas cotidianas vivenciadas por esses sujeitos, devem ser evidenciadas nos conteúdos ensinados, fazendo a relação com os saberes científicos/saber escolar, propiciando para que eles percebam que querendo ou não em algum momento de suas vidas irão utilizar esses conhecimentos dito científicos e evidenciando a utilização dos diferentes saberes dentro da sala de aula e fora dela.

\section{CONSIDERAÇÕES FINAIS}

O presente trabalho que é fruto de minha monografia de conclusão de especialização na qual teve como objetivo discutir minha experiência como professor de matemática na escola Carlos Marighella, a partir de narrativas constituídas por memórias evocadas por fotografias, relacionada com uma perspectiva da Etnomatemática. 
Nesse processo de construção, foram utilizadas as fotografias como instrumento/dispositivo para auxiliar-me nessa rememoração, pois, ao olhar essas fotografias me vêm na memória momentos únicos desenvolvidas ao longo de minha prática, em especial na escola Carlos Marighella com a turma de 4ํano, para além disso, me faz pensar na minha história de vida, que foi construída e constituída ao longo das minhas vivências e experiências nos mais diversos espaços, sendo a escola Carlos Marighella parte importante na minha história.

Quando faço uma retrospectiva, buscando minhas memórias de estudante, na qual tinha uma paixão e um desejo de ser professor de matemática, percebo e busco desenvolver dentro de minhas práticas um ensino que vai para além daquilo que foi o meu processo educativo, um ensino que não dialogava com minha realidade. Narrar uma parte de minha história enquanto professor de matemática, educador popular, me faz sentir que estou trilhando no rumo certo, daquilo que acredito, numa educação emancipadora, na formação de sujeitos pensantes.

Não foi fácil fazer essas narrativas, tendo em vista que nossas memórias são falhas, nem sempre conseguimos rememorar tudo o que se passou da forma como foi desenvolvida, as vezes tive que parar e ficar pensando sobre os fatos ocorridos, mesmo tendo as fotos para me ajudar nesse processo e, em meio a esses pensamentos me vinha a época de estudantes, das possibilidades pela qual eu poderia ter aprendido matemática e outras áreas do conhecimento.

As fotografias, aqui utilizadas, fizeram-me perceber as belezas e as possibilidades de se trabalhar o ensino de matemática, e ficava percebendo minha evolução, os aprendizados, e as possibilidades em que poderia explorar mais além do que foi naquele momento. No evocar dessas memórias, enquanto professor de matemática, que busco trabalhar na perspectiva da Etnomatemática, não tem como fugir das memórias de estudante, que de certa forma ela influência, seja porque se teve um processo educacional que te influenciou positivamente ou negativamente, que partindo do processo educacional você vai fortalecer ou negar no seu ambiente de trabalho e convivência. Confesso que essas memórias de estudante têm grande influência dentro de minhas práticas docente.

Essa experiência pedagógica desenvolvida no âmbito da Escola Carlos Marighella com estudantes do $4^{\circ}$ ano, foi trabalhada a partir dos princípios da Educação do Campo e da Etnomatemática, levando para sala de aula seus 
saberes, dialogando com o saber cientifico, ampliando e valorizando seus conhecimentos. Desta forma, esta experiência propicia aprendizagem mútua, tanto os estudantes aprendem, como eu enquanto educador estou aprendendo com meus estudantes, e buscando melhorar minhas práticas como docente.

No desenvolvimento dessas atividades, busquei trabalhar os conteúdos escolares partindo dos saberes locais da comunidade, mostrando que é possível inserir a realidade dos sujeitos no ambiente escolar, fortalecendo e ampliando seus saberes. Trabalhar o ensino de diferentes áreas do conhecimento de forma interdisciplinar, pude proporcionar aos estudantes maiores significado dos conteúdos para sua vida diária. Para desenvolvermos práticas como essa, é necessário compreendermos o contexto em que estamos inseridos e buscar práticas que reconheça as especificidades de cada grupo social. Com isso, essa prática pedagógica desenvolvida contribuiu para uma reflexão da minha prática enquanto professor, e para além dela, pois, desenvolver atividades que fortaleza os conhecimentos da comunidade deve ser uma das principais bandeiras do professor.

Desenvolver práticas como essa, traz uma importante contribuição não só para minha formação enquanto educador do campo, militante da Educação do Campo, mas para fortalecer as lutas desses sujeitos, e dizer para nossa sociedade que, apesar do não apoio por parte do poder público, por falta de investimentos, espaços adequados, desenvolvemos práticas pedagógicas que amplie os conhecimentos dos camponeses, bem como lhes é oferecido uma educação de qualidade, não uma educação qualquer, mais uma educação emancipatória voltada para os interesses dos sujeitos do campo. 


\section{REFERÊNCIAS}

Brasil. Secretaria de educação fundamental. Parâmetros curriculares nacionais: terceiro e quarto ciclos do ensino fundamental: matemática- brasília: $\mathrm{mec} / \mathrm{sef}$, 1998.

Bourdieu, pierre. Les rites comme actes d'institutions. Ln: centllvres, p. Et harinard, j. (dir.). Les rites de passages aujourd'hui. Actes du colloque de neuchâtel, 1987.

Bosi, eclêa. Memoria e sociedade, lembranças de velho. T. A. Quelroz, editor, Itda. Rua joaquim floriano, 733 - 04534 são paulo, sp - 1979

Dicionário da educação do campo. / organizado por roseli salete caldart, isabel brasil pereira, paulo alentejano e gaudêncio frigotto. - rio de janeiro, são paulo: escola politécnica de saúde joaquim venâncio, expressão popular, 2012.

D'ambrósio, ubiratan. Etnomatemática - elo entre as tradições e a modernidade/ ubiratan d'ambrósio. - 5. Ed.; 2. Reimp. - belo horizonte: autêntica editora, 2017.

D’ambrosio, ubiratan o programa etnomatemática: uma síntese. Acta scientiae, v.10, n.1, jan. /jun. 2008

Freire, paulo. Educação e atualidade brasileira/ paulo freire; prefácio fundadores do instituto paulo freire; organização josé eustáquio romão; depoimentos paulo rosa, cristina helniger freire. - 3. Ed. - são paulo: cortez; instituto paulo freire, 2003.

Freire, paulo. Pedagogia do oprimido. 17ํㅡ ed. Rio de janeiro, paz e terra, 1987.

Freire, paulo. Educação como prática da liberdade. Editora paz e terra, 1967.

Fressnot, alain. Desmundo. Brasil: sony pictures. Drama,2003.

Knijnik, gelsa. O que os movimentos sociais têm a dizer à educação matemática? Educação matemática: um compromisso social. Recife, 15 à 18 de julho de 2004. Anais do viii enem - palestra. Disponível em<http://www.sbembrasil.org.br/files/viii/pdf/15/pa06.pdf>. Aceso em: 15 de abr.2021.

Lins, romulo campos; gimenez, joaquim. Perspectivas em aritmética e álgebra para o século xxi. 7. Ed. - campinas-sp: papirus, 2006. - (coleção perspectivas em educação matemática)

Mello, guiomar namo de. Transposição didática, interdisciplinaridade e contextualização. Disponível em: < http://www.namodemello.com.br/pdf/escritos/outros/contextinterdisc.pdf >. Acesso em: 20. Jun. 2017.

Moita, maria da conceição. Percursos de formação e de trans-formação. In: nóvoa, antonio. Vidas de professores. Porto: porto editora, 1995. 
Romaneli, otaiza de oliveira. História da educação no brasil. 25aㅡ ed. Petrópolis: editora vozes,2001. P.33 a 46.

Suleiman, amal rahif. Empregando a matemática: uma experiência com o mundo do trabalho. Revista eletrônica de educação, 2013. V. 7, n. 3, p.238-247, issn 1982-7199 | disponível em: <http://www.reveduc.ufscar.br> acesso em: 10 de jan. 2021.

Tomaz, vanessa sena; david maria; manuela martins soares. Interdisciplinaridade e aprendizagem da matemática em sala de aula. - belo horizonte: autêntica editora, 2008. - (coleção tendências em educação matemática). 